But we must not forget that the science of language is still a young science. Its followers are still engaged in laying its foundations and testing their strength. The problems that await solution are numerous and important. So far as our evidence goes at present, it tends to show that the languages of the world have sprung from an infinite number of separate sources, but it remains to be seen whether future discoveries will not reverse this conclusion. Then, again, there is the question of roots. All comparative philologists admit that roots are the ultimate elements into which language can be decomposed, but it is still a question whether the roots discovered by the grammarian once formed a spoken language, or whether they are but grammatical figments which are the best representatives we can obtain of the early condition of speech. Equally disputed is the question whether the different classes of language-inflectional, agglutinative, polysynthetic, and isolating-are to be regarded as constituting separate streams of linguistic development from the first, or a single strean which has branched out into separate ones. It is unquestionable that a large part of flection can be shown to have had an agglutinative origin, it is also unquestionable that the phenomena of isolation are to be met with in the inflectional languages, and the phenomena of flection in the isolating languages; but it is asked whether this would have been possible if each class had not had a definite tendency to flection or isolation from its starting-a standard, that is, to which all forcign elements introduced into the language were made to conform. Such are some of the questions which still remain to be answered; and if we are to judge from the rapid progress already made by the science of language, the answers will not be long in coming.

\section{A. H. SAYCE}

\section{OUR BOOK SHELF}

Rutiments of Geology. By Samuel Sharp, F.S.A., F.G.S. Second Edition. (London: Edward Stanford, 1876. )

THE author of this little manual, which is designed for the use of schools and junior students, has evidently taken considerable pains to malke his work fairly represent the existing state of geological knowledge. He has, moreover, succeeded in conveying in simple language an idea, not only of the conclusions attained, but of the processes of investigation and reasoning, followed by the geologist in his researches, and we regard the book as well adapted to introduce a beginner to the study of the science, and to prepare him for the profitable perusal of more extended treatises. As compared with some of the similar introductory text-books of the science, which have recently been published, Mr. Sharp's manual labours under the disadvantage of being somewhat inadequately illustrated, for we find in it only a few diagrams and no figures of fossils. This second edition, however, is certainly a considerable improvement upon the first, and the division of Physical Geology has received much more full and careful treatment ; the extent of the additional matter being sufficient to increase the number of pages of the book from 126 to 204 .

South Australia: its History, Resources, and Productions. Edited by William Harcus. Illustrated with photographs taken in the Colony. Published by authority of the Government of South Australia. (London: Sampson Low and Co., 1876 .)

THE nature of this handsome volume may be learned from the fact that it has been prepared to accompany the speci- mens of South Australian products and industries sent to the Philadelphia Exhibition. It contains a vast amount of the most useful information on nearly all matters connected with the colony, gives an excellent idea of its present condition, and is likely to be of great use to intending settlers. Mr. Harcus, who edits the volume, writes also one half of it, treating of the social, political, and industrial aspects of the colony. In a series of valuable appendices, Dr. Schomburgk treats of the flora of South Australia, Mr. Waterhouse of its fauna, Mr. J. B. Austen of mines and minerals, while Mr. Josiah Boothby contributes a statistical sketch of the colony, and Mr. Charles Todd treats of its observatory and meteorology. There are two very useful maps, while the illustrations are nearly all good and interesting.

\section{LETTERS TO THE EDITOR}

[ The Editor does not hold himself responsible for opinions expressed by his correspondents. Neither can he undertake to return, or to correspond with the writers of, rejected manuscripts. No notice is taken of anonymous communications.]

The Spelling of the Name "Papúa"

I QUITE agree with Mr. Whitmee's objections to Engiish orthography of foreign words (see NATURE, vol, xiv. p. $4 \delta$ ), but in this case $I$ intended to show at a glance to nonlinguistic readers that the accent in the word Papúa must be on the second syllable, and not on the first. The Germans write "Papua," and pronounce "Pápı̌a" (as they pronounce "Mántúa," "Pádŭa," \&c.). This being wrong, and fancying that in Eng. land the same mistake is ofien made, I wrote "Papooa," which leaves no uncertainty in respect to pronunciation. I confess that it would have been more convenient to retain "Papua," and remark in a note that the accent must be on the "u." In a linguistic work I should never have proposed "Papooa," but it cannot be supposed that every reader of NA'URe knows what Marsden pointed out in 1812. In German I write "Papria," and perhaps the same mocle would be the most convenient in English. It is known that the French use "Papoula," the Dutch "Papoea," the Malay "Papuwah." In these cases the pronunciation may not be questionalile, as it is in Germanl and English, if written "Papua."

The most interesting point in Mr. Whitmee's letter is, no doubt, the amnouncement of a comparative grammar and dictionary of all the principal Malayu. Polynesian dialects; and those interested in these studies will certainly be anxious to receive such a valuable increase to their knowledge.

Dresden, May 23

\section{A. B. MEYER}

\section{New Zealand Prehistoric Skeleton}

Among the "Notes" in NatURE, vol, xiii. p. 196, just come to hand, you give an extract from the Order Paper of the Legislative Council of New Zealand concerning the remains of a sup. posed "prehistoric man," regarding which a motion for an inquest was tabled by Mr. Waiter Mantell. As you correctly report, this skeleton was excavated under my direction in the so-called Moa-bone Point Cave, hut it was not found in the lower beds containing Moa-bones, but in a much more recent formation, and to which I assigned a comparatively modern dale.

You state that "I hold strongly to the palrevithic age of the deposits," but I am at a loss to conceive what ground you have for such an assertion, and as I can only conclude that you received your information direct from New Zealand, I beg to forward you herewith for your perusal a copy of my pal:er reporting the excavations and my views thereupon.

With regard to the motion itself, which was treated througly. out the colony as a joke, it is sufficient to state that $\mathrm{Mr}$. Walter Mantell is the recognised jester of the Legislative Council, and that even science does not escape his attempted witicisms. I may add that the Hon. Dr. Pollen, the Premier of the Colcny, also treated the motion as a joke, and offered Mr. Mantell the office of coroner for the proposed investigation.

Although Mr. W. Mantell, F.G.S., stated, when speaking on his motion (see Hansard, 1875, p. 548), that "he glonied in the fact that he was not a scientific man, and he did hope he ruould be able to go to his grate without incurring that disgrace;" never. 